\title{
Parallels and differences in the treatment of metaphor in relevance theory and cognitive linguistics*
}

DEIRDRE WILSON

Abstract

Both cognitive linguists and relevance theorists are developing original approaches to metaphor. Both shed new light on old debates and suggest fruitful directions for research. Although there has so far been little interaction between the two approaches, Raymond Gibbs and Markus Tendahl (2006, 2008) have recently begun to compare them and consider how they might be combined. This paper is intended as a contribution to that debate. After outlining some parallels and differences between the two approaches, I will discuss how they might fit together to give a fuller picture of the role of metaphor in language and thought.

\section{Introduction}

In the last 25 years, traditional approaches to metaphor (in classical rhetoric or Gricean pragmatics, for instance) have been increasingly questioned on both theoretical and experimental grounds. Where traditional approaches treat metaphor as a departure from a maxim, norm, or convention of literal truthfulness, there is a growing consensus that the Romantic critics of classical rhetoric were right to see metaphor as entirely normal, natural and pervasive in language. Where traditional approaches treat metaphor as a purely decorative device with little or no cognitive significance, it is increasingly recognized that most metaphors cannot be paraphrased in literal terms without loss to the meaning. Relevance theorists and cognitive linguists, who have both explicitly distanced themselves from traditional approaches to metaphor, are part of this growing consensus.

However, relevance theorists and cognitive linguists see metaphor as entirely normal and natural for rather different reasons. Cognitive linguists have argued that metaphor is pervasive in language because it is pervasive in thought. ${ }^{1}$ As Lakoff and Johnson (1980: 153) put it, "Metaphor is primarily a 
matter of thought and action and only derivatively a matter of language." On this approach, linguistic metaphors are treated as surface reflections of underlying conceptual mappings between different cognitive domains (e.g., the domains of love affairs and journeys, theories and buildings, arguments and fights), and have their roots in cognition rather than communication. Relevance theorists, on the other hand, have argued that metaphor arises naturally in linguistic communication, as language is loosely used in an attempt to convey complex thoughts that may be vague, but need not themselves be metaphorical. On this approach, there is a continuum of cases between literal talk, loose talk, hyperbole and metaphor, none of which is necessarily a surface reflection of any pre-existing conceptual mapping. As Sperber and Wilson (2008: 84) put it, "We see metaphors as simply a range of cases at one end of a continuum that includes literal, loose and hyperbolic interpretations. In our view, metaphorical interpretations are arrived at in exactly the same way as these other interpretations. There is no mechanism specific to metaphor, no interesting generalisation that applies only to them."

Until recently, relevance theorists and cognitive linguists have been more concerned with developing and applying their own approaches than comparing them with those of others. A notable exception has been Raymond Gibbs, whose pioneering experimental work draws on elements of both cognitive linguistics and relevance theory, and has had an important influence on both. In two recent papers, Gibbs and Markus Tendahl $(2006,2008)$ suggest that, despite some fundamental differences, relevance theory and cognitive linguistics may be seen as providing complementary rather than contradictory approaches to metaphor, and have begun to consider how they might be combined:

Many metaphor scholars [ ... ] see these alternative theories as being radically different. After all, cognitive linguistics and relevance theory adhere to very different goals and methodological assumptions. [...] These different goals and working assumptions are so great, in fact, that few metaphor scholars have tried to systematically compare these two theories to understand how and why they differ. Yet there is also a small underground movement, as we have personally noted at various metaphor conferences, to begin thinking about ways that cognitive linguistics and relevance theory perspectives on metaphor may be complementary. These discussions arise as metaphor scholars $[\ldots]$ struggle with the deficiencies of each theory and begin to understand that both perspectives have something very important to contribute toward a comprehensive, cognitive theory of metaphor. (Tendahl and Gibbs 2008: 1824)

In this paper, I would like to take up Gibbs and Tendahl's challenge and suggest some ways in which the two approaches to metaphor might combine.

One way of reconciling the apparently incompatible views of relevance theorists and cognitive linguists about the origin of metaphors would be to look for evidence that some metaphors arise in language use and others in thought. 
As Gibbs and Tendahl point out, relevance theorists and cognitive linguists tend to focus on metaphors of rather different types. Whereas relevance theorists offer many analyses of standard examples such as (1a)-(1c), which are familiar from classical rhetoric, cognitive linguists have been more concerned with examples such as (2a)-(2c), which they see as reflecting conceptual mappings across cognitive domains:

(1) a. Robert is a computer.

b. Susan is a wild rose.

c. Sally is an angel.

(2) a. Bill's marriage is on the rocks. (LOVE IS A JOURNEY)

b. He destroyed my defenses. (ARGUMENTS ARE FIGHTS)

c. Your theory is falling apart. (THEORIES ARE BUILDINGS)

For anyone attempting a unitary account of metaphor, the challenge would be to show how both types of example can be analyzed in the same way. In fact, relevance theorists have consistently argued that terms such as "metaphor" and "irony" pick out a variety of loosely related phenomena that do not necessarily all work in the same way: In other words, they have consistently argued that metaphor and irony are not natural kinds. There is, thus, a genuine question about whether the examples in (1) and (2) exploit the same cognitive and communicative mechanisms, and if so, whether they fit better with the relevance theory or the cognitive linguistics approach.

A further way of exploring the possible interrelations between the relevance theory and cognitive linguistic treatments of metaphor would be to look at the central role of concepts in both approaches. According to relevance theory, hearers understand linguistic metaphors by using linguistic and contextual clues to create new "ad hoc" (occasion-specific) concepts, which are typically not identical to any of the concepts linguistically encoded by the metaphorically used word or phrase, although they inherit some of their inferential properties from those concepts. It might then be reasonable to assume that the repeated use of linguistic metaphors linking items from distinct cognitive domains might set up patterns of conceptual activation similar to those that cognitive linguists see as characteristic of conceptual metaphor. To take just one illustration, many cultures have a set of flower metaphors (e.g., daisy, lily, violet, rose) that are typically applied to women. From a cognitive linguistics perspective, these linguistic metaphors might be seen as surface reflections of an underlying conceptual metaphor WOMEN ARE FLOWERS, based on systematic correspondences between the domains of women and flowers. From a relevance theory perspective, these linguistic metaphors would be seen as originating in creative uses of language for opportunistic communicative purposes, which, if repeated often enough, might result in the setting up of systematic correspondences between 
the domains of women and flowers. Here again, there is a genuine question about whether, and to what extent, conceptual cross-domain mappings originate in language use, and are therefore to be explained at least partly in pragmatic terms.

My aim in this paper is to argue that relevance theory offers a genuine alternative to cognitive linguistic approaches to metaphor, and can complement these approaches in at least two ways: first, by showing how some metaphors can arise as creative loose uses of language, and second, by showing how the idea that linguistic metaphors create new "ad hoc" concepts has interesting implications for the cognitive linguistics treatment of metaphor. I hope the resulting picture will provide a basis for future discussion and stimulate further research on the possible interrelations between the two approaches.

\section{Metaphor and lexical pragmatics: How word meanings are modified in use}

The aim of a pragmatic account of metaphor is to explain how hearers recognize the intended meaning of a metaphorical utterance in context. According to relevance theory, linguistic metaphors originate as loose uses of language, in which a word or phrase is used to communicate a novel "ad hoc" concept which is broader (more general) than the encoded lexical meaning. In the metaphor Robert is a computer, for instance, the sentence uttered is (3a), and the encoded lexical meaning of the word computer is the concept COMPUTER, which denotes a certain type of machine used for processing information:

\section{(3) a. Sentence uttered: Robert is a computer \\ b. Lexical meaning of "computer": COMPUTER (i.e., a type of machine)}

What the speaker communicates by use of the word computer in (3a), however, is not the lexical meaning COMPUTER but an "ad hoc" concept with a broader denotation, which is constructed in the course of interpreting (3a), and which applies not only to actual computers, but also to people who share some of the encyclopedic properties of computers (for instance, they process information accurately, lack common sense, intuition, human feelings, and so on). Thus, what might be communicated by uttering (3a) on a particular occasion could be represented as in (4), where COMPUTER* is a broader, "ad hoc" concept the denotation of which includes both computers and some humans:

(4) a. Speaker's explicit meaning: Robert is a COMPUTER*

b. Implicatures: Robert lacks feelings, processes information well, etc.

Relevance theory's treatment of metaphor is part of a more general approach to lexical pragmatics, which is based on the following assumptions. First, the 
lexical meaning of a word is merely a clue to the speaker's meaning, and the concept communicated by use of a word typically differs from the lexical meaning. Second, metaphor is just one of many ways in which lexical meanings can be modified in use. The concept communicated by use of a word may be narrower (more specific) or broader (more general) than the lexical meaning (or it may be narrower in some respects and broader in others, as is often the case in metaphor). Third, there is a continuum of cases of broadening, ranging from strictly literal use, through various shades of approximation to hyperbole and metaphor, with no sharp cut-off point between them. Fourth, all these cases are interpreted in the same way: There are no special pragmatic principles or mechanisms that apply only to metaphors. And fifth, contrary to what is generally assumed in Gricean pragmatics and philosophy of language, the concept communicated by use of a word contributes to what the speaker is taken to have asserted (i.e., the truth-conditional content of the utterance), and not only to what is implicated (Wilson and Carston 2007; Sperber and Wilson 2008). Since metaphorical uses of language - just like strictly literal uses — contribute to truth-conditional content and fall within the scope of logical connectives, they cannot be dismissed as marginal to the concerns of linguistics proper. ${ }^{2}$

The case of lexical narrowing can be illustrated using an example from Fauconnier and Turner (2002: 27). As Fauconnier and Turner point out, the phrase red pencil is semantically very vague: The concept RED PENCIL applies to any pencil that stands in some relation to the color red, e.g., pencils that are painted red, pencils that write in red, pencils smeared with lipstick, pencils used to record the activities of a team dressed in red, and so on. Still, when a teacher marking an essay says, "I need a red pencil," she will certainly have some specific sub-type of red pencil in mind, and in order to understand her, the hearer must infer what particular type of red pencil this is. In other words, the teacher must be understood as asking not simply for a RED PENCIL, but for a RED PENCIL*, where RED PENCIL* denotes the particular sub-type of pencil she has in mind. The interpretation of virtually any utterance involves some such form of lexical narrowing, and one of the goals of lexical pragmatics is to explain how it is achieved.

Similarly, the interpretation of virtually any utterance involves some form of lexical broadening, in which the concept communicated by use of a word is more general than the lexical meaning. The broadening can be almost imperceptible, as in the following cases of approximation:
(5) a. The play starts at 7 .
b. Jane's hair is straight.

The speaker of (5a) would generally be understood as communicating that the play starts, not at 7 on the dot, but at approximately 7 (i.e., $7^{*}$ ), and the speaker 
of (5b) would generally be understood as communicating that Jane's hair is, not straight in the strict geometric sense, but merely straight in an approximate sense appropriate to human hair (i.e., STRAIGHT*). The interpretation of virtually any utterance involves similar types of approximation, where a term with a strict meaning is loosely applied to what Lasersohn (1999) calls a "penumbra" of cases that fall just outside the linguistically specified denotation.

According to relevance theory, approximation shades off imperceptibly into hyperbole. Consider the utterances in (6):

(6) a. The lecture hall was empty.

b. The water is freezing.

Let's suppose that empty in (6a) is narrowed to mean "empty of people" (as opposed, say, to "empty of furniture"). Then the utterance would traditionally count as an approximation if the speaker is taken to mean that there were only a very few people present. In this case, use of the word empty would be understood as intended to convey a concept EMPTY*, meaning "close enough to EMPTY for the differences to be inconsequential." By contrast, the same utterance would traditionally count as a hyperbole if the speaker is taken to mean that, although many people were present, there were more empty seats than might have been expected or desired. In this case, use of the word empty would be understood as intended to convey a broader concept EMPTY**, meaning "closer to EMPTY than expected or desired." Here, it is easy to see there is a whole continuum of intermediate cases, with no sharp cut-off point between approximation and hyperbole. For relevance theorists, this is not a matter for concern, since they claim that the distinction between approximation and hyperbole has no theoretical significance: An utterance does not have to be recognized as an approximation or hyperbole to be understood, no special interpretive mechanisms are needed in either case, and both are understood in the same way. However, for theories that draw a sharp distinction between literal and figurative uses of language, or that treat approximation and hyperbole as involving different interpretive mechanisms, the fact that there is no clear cut-off point between them should be a serious matter for concern. Similar points apply to (6b), where there is a continuum of cases between the use of freezing to mean 'actually FREEZING,' 'almost FREEZING,' and 'closer to FREEZING than expected or desired.'

Although metaphor has received a great deal of attention in cognitive linguistics, and in philosophy and psychology more generally, hyperbole has received much less attention. According to relevance theory, there is no clear dividing line between hyperbole and metaphor, and an adequate account of metaphor should therefore apply to hyperbole in the same way. To illustrate, consider the utterances in (7): 
(7) a. John is a giant.

b. John is as tall as the Eiffel Tower.

c. John is incredibly tall.

One possible way of distinguishing hyperbole from metaphor would be to treat hyperbole as involving an increase in quantity along a single dimension (e.g., height), while metaphor would involve a qualitative change (so that the speaker in metaphorical uses of (7) would be understood as attributing to John properties not directly linked to height). According to this criterion, (7a) would count as a hyperbole if taken to mean that John is very tall for a human, and as a metaphor if taken to mean that John stands out for other reasons than simply his height. However, again there is a gradient between the two types of case, with increases in quantity along a single dimension ultimately leading to a qualitative change. For instance, all three utterances in (7) activate thoughts of John's height as being not merely human but superhuman, and these carry implications for other properties than simply his height. Thus, hyperbole shades off imperceptibly into metaphor, and is not reducible to an ornamental device with little or no cognitive significance. From a cognitive linguistics perspective, if metaphor is analyzed in terms of cross-domain mapping, it follows that hyperbole must be analyzed in a similar way. But while hyperboles such as (7a) or (7b) might conceivably be analyzed in terms of such mappings (e.g., between the domains of people and superhumans, or people and buildings), others, such as (7c), have no obvious analysis in conceptual metaphor terms.

The relevance theory approach to lexical pragmatics suggests that it should be possible to find a single utterance that can be intended and understood literally, loosely, hyperbolically, or metaphorically on different occasions. Here is an illustration:

(8) The audience slept through the lecture.

In certain circumstances, an utterance of (8) might be intended and understood as making the very strong claim that the audience was literally asleep throughout the lecture. In other circumstances, it might be intended and understood as making the slightly weaker claim that the audience was, if not literally asleep, at least on the point of falling asleep during the lecture; in traditional terms, it would then count as an approximation. In different circumstances, (8) might be intended and understood as claiming, still more weakly, that the audience was, if not asleep or on the point of sleep, at least in a physical state of drowsiness during the lecture: In traditional terms, it would then count as a hyperbole. Finally, in many circumstances, (8) might be intended and understood as making a weaker claim still: that the audience, if not literally asleep, on the point of sleep or even feeling physically drowsy, was at least extremely bored and unresponsive during the lecture (in traditional terms, it would then count as a 
metaphor). This example illustrates two central features of relevance theory's approach to lexical pragmatics - that there is a continuum of cases between literal use, approximation, hyperbole, and metaphor, and that the choice between different possible interpretations is heavily context-dependent.

The flexibility and context-dependence of lexical-pragmatic interpretation presents a challenge for both relevance theory and cognitive linguistics. The goal of pragmatics is to explain how hearers infer the speaker's intended meaning from clues provided by the utterance and the context. But if utterance interpretation typically involves the narrowing or broadening of lexical meaning, as relevance theory claims, how do hearers ever recognize the speaker's intended meaning? What factors trigger the narrowing or broadening process? What determines the direction it takes and when it stops? Similarly, if utterance interpretation typically involves the use of conceptual metaphors, blending, domain mapping, and so on, as cognitive linguistics claims, how do hearers ever recognize the speaker's intended meaning? What factors trigger the mapping/ blending process? What determines the direction it takes, and when it stops? Here, relevance theory has a concrete proposal to make, which may be of interest to cognitive linguists attempting to answer parallel questions about how linguistic metaphors are used and understood. In the next section, I will briefly outline the basic features of the relevance-theory approach and illustrate its application to metaphorical examples such as those in (1) and (2) above.

\section{Relevance theory and metaphor interpretation}

The goal of lexical pragmatics is to explain how lexical meanings are adjusted in the course of communication. The explanation suggested by relevance theory is that lexical meanings are adjusted in order to satisfy expectations of relevance. In a nutshell, the theory claims that utterances addressed to one raise expectations of relevance not raised by other stimuli, and that hearers are entitled to treat the encoded linguistic meaning as a clue to the speaker's meaning, and to follow a path of least effort in adjusting this encoded meaning to a point where it yields an overall interpretation that satisfies those expectations.

In more technical terms, relevance is defined as a property of inputs to cognitive processes (whether external stimuli, which can be perceived and attended to, or internal representations, which can be stored, recalled, or used as premises in inference). An input is relevant to an individual when it connects with available contextual assumptions to yield positive cognitive effects (for instance, true contextual implications, warranted strengthenings, or revisions of existing assumptions). For present purposes, the most important type of cognitive effect is a contextual implication: an implication deducible from 
input and available contextual assumptions together, but from neither input nor contextual assumptions alone. Other things being equal, the more implications derived, and the smaller the mental effort required to represent the input, access an appropriate set of contextual assumptions and derive these implications, the greater the relevance of the input to the individual at that time. ${ }^{3}$

Relevance theory is based on two general claims about the role of relevance in cognition and communication:

\section{Cognitive Principle of Relevance:}

Human cognition tends to be geared toward the maximization of relevance.

\section{Communicative Principle of Relevance:}

Every act of overt intentional communication conveys a presumption of its own optimal relevance.

The Cognitive Principle of Relevance yields a variety of predictions about human cognitive processes. It predicts that the human cognitive system has evolved in such a way that our perceptual mechanisms tend spontaneously to pick out potentially relevant stimuli, our memory retrieval mechanisms tend spontaneously to activate potentially relevant assumptions, and our inferential mechanisms tend spontaneously to process them in the most productive way. This principle has essential implications for human communication. In order to communicate, the communicator needs her audience's attention. If attention tends to go automatically to what seems most relevant at the time, then the success of communication depends on the audience taking the utterance to be relevant enough to be worthy of attention. Wanting her communication to succeed, the communicator, by the very act of communicating, indicates that she wants the audience to see her utterance as relevant, and this is what the Communicative Principle of Relevance states.

According to relevance theory, the presumption of optimal relevance conveyed by every utterance is precise enough to ground a specific comprehension heuristic that hearers can use in interpreting the speaker's meaning:

\section{Presumption of optimal relevance}

a. The utterance is relevant enough to be worth processing.

b. It is the most relevant one compatible with the communicator's abilities and preferences.

\section{Relevance-guided comprehension heuristic}

a. Follow a path of least effort in constructing an interpretation of the utterance (e.g., in resolving ambiguities and referential indeterminacies, adjusting lexical meaning, supplying contextual assumptions, deriving implications, etc.).

b. Stop when your expectations of relevance are satisfied. 
A hearer using this heuristic during online comprehension should proceed in the following way. The aim is to find an overall interpretation that satisfies the presumption of optimal relevance. To achieve this aim, he must enrich the decoded sentence meaning at the explicit level and complement it at the implicit level by supplying contextual assumptions that will combine with it to yield enough implications to make the utterance relevant in the expected way. What route should he follow in disambiguating, assigning reference, adjusting lexical meaning, constructing a context, deriving conclusions, etc.? According to the relevance-theoretic comprehension heuristic, he should follow a path of least effort in looking for implications and stop at the first overall interpretation that yields enough implications to satisfy his expectations of relevance.

As noted above, the goal of lexical pragmatics is to explain what triggers pragmatic adjustment processes such as lexical narrowing and broadening, what direction they take, and when they stop. Relevance theory suggests the following answers to these questions. First, lexical adjustments are triggered by the search for an interpretation that yields enough implications to satisfy the expectations of relevance raised by the utterance. Second, they follow a path of least effort, starting with the most accessible contextual assumptions, the most accessible narrowings or broadenings, the most accessible implications. Third, they involve mutually adjusting tentative hypotheses about contextual assumptions, explicit content (including adjusted "ad hoc" concepts) and implications so that the resulting overall interpretation satisfies the expectations of relevance raised by the utterance. And finally, the adjustment process stops when the expectations of relevance raised by the utterance are satisfied (or abandoned). I will shortly illustrate how this is done.

As noted above, an important ingredient of this account is the idea that lexical comprehension typically involves the construction of an "ad hoc" concept, or occasion-specific sense, which may be broader or narrower than the encoded lexical meaning. Use of the term "ad hoc concept" in this connection is often traced to the psychologist Lawrence Barsalou $(1987,1993)$, whose work on categorization showed that prototypical narrowing (i.e., the interpretation of a general term as picking out the subset of prototypical category members) was much more flexible and context-dependent than had previously been assumed. In later work by the psycholinguist Sam Glucksberg and colleagues (2001), and by relevance theorists (e.g., Carston 2002, Wilson and Sperber 2002), it was suggested that the outcome of the ad hoc concept construction process could also be a broadening of the encoded lexical meaning. This opened up the possibility of a unified account on which lexical narrowing and broadening (or a combination of the two) are the outcomes of a single interpretive process that fine-tunes the interpretation of almost every word.

A second important ingredient of this approach to lexical pragmatics is the assumption that lexical concepts (e.g., COMPUTER, GIANT) provide access to an 
ordered array of encyclopedic information about items falling under the concept. This encyclopedic information is not seen as part of the semantic content of the concept, but as providing a reservoir of potential contextual assumptions that, when added to the context, can contribute to relevance by yielding contextual implications. A given encyclopedic assumption will be more or less accessible on different occasions, and will yield different potential implications depending on what else is present in the utterance and the discourse context. It will, therefore, make different contributions to relevance on both the processing effort and cognitive effect sides. Thus, a speaker who intends her utterance to be understood in a certain way should make sure that the appropriate encyclopedic assumptions are accessible enough to be selected, added to the context, and used to derive the intended implications by a hearer using the relevance-theoretic comprehension heuristic.

To illustrate how this account might apply in a case of lexical narrowing, consider how the utterance in (9) might be understood by a hearer using the relevance-theoretic comprehension heuristic:

(9) Teacher, carrying a pile of essays: I need a red pencil.

As noted above, the concept RED PENCIL is semantically vague: Its denotation includes any pencil that stands in some relation to the color red, and it will provide access to a huge array of encyclopedic information about such pencils and their uses. Still, according to relevance theory, the utterance of (9) creates a presumption of relevance that entitles the addressee to follow a path of least effort in constructing an overall interpretation on which the utterance yields enough implications to make it relevant in the expected way. According to spreading activation models of memory, the most accessible assumptions in the encyclopedic entry for RED PENCIL at any given point will be those simultaneously activated by several features of the utterance and the discourse context. With (9), the fact that the speaker needs a RED PENCIL should activate encyclopedic information about the uses to which RED PENCILS can be put. The fact that the speaker is a teacher will add an extra layer of activation to information about the uses of RED PENCILs by teachers, and this will include the information that teachers use pencils that write in red when marking essays. The fact that the teacher is carrying a pile of essays will add a further layer of activation to this same encyclopedic assumption that teachers use pencils that write in red when marking essays, which should therefore be the most accessible assumption in the encyclopedic entry for RED PENCIL during the interpretation of the utterance in (9). By assuming that the phrase red pencil was intended to convey not the very general encoded concept RED PENCIL but the narrower concept RED PENCIL * (i.e., 'pencil used to write in red'), the hearer can thus arrive at an overall interpretation that satisfies his expectation of relevance by implying that the teacher wants him to help her find a RED PENCIL*. According to the relevance- 
theoretic comprehension heuristic, he is justified in making this assumption, because it is the least effort-demanding way of finding an overall interpretation that yields enough implications to make the utterance relevant in the expected way.

To illustrate how the same account might apply in a case of lexical broadening, consider how the utterance in (8) above (repeated below for convenience) might be understood by a hearer using the relevance-theoretic comprehension heuristic:

(8) The audience slept through the lecture.

On a Gricean account, (8) should have four distinct interpretations: as a literal assertion, an approximation, a hyperbole, or a metaphor. Of these, the hearer should test the literal interpretation first, and consider a figurative interpretation only if the literal interpretation blatantly violates the maxim of truthfulness. However, the fact that there is both experimental and introspective evidence against the Gricean account when construed as a model of utterance comprehension (e.g., Gibbs 1994, Glucksberg 2001, Wilson and Sperber 2002) justifies the search for an alternative analysis of (8). According to relevance theory, there is no presumption that literal interpretations are the first to be tested. The encoded concept SLEEP is merely a point of access to an ordered array of encyclopedic assumptions from which the hearer is expected to choose in constructing an overall interpretation that satisfies his expectations of relevance. Here, the encyclopedic entry for SLEEP might give access to the following type of assumptions:

\section{Encyclopedic entry for SLEEP:}

a. become mentally disengaged

b. lose interest in one's surroundings

c. become motionless and unresponsive

d. gradually lose consciousness

e. undergo physical changes (snoring, slowed heart-rate, deep breathing, etc.)

In different discourse contexts, different members of this set will be more or less accessible, and depending on which of them are chosen, the result will be a relatively narrower or broader interpretation of the word slept. Here, a literal interpretation will result only if assumption (e) is added to the context. However, since it is extremely rare for the audience actually to lose consciousness at a lecture, this assumption is unlikely to be strongly activated in that particular discourse context. By contrast, the mention of an audience at a lecture is quite likely to activate assumptions such as (a)-(c), having to do with loss of interest, unresponsiveness, and mental disengagement. These assumptions, if added to the context, would contribute to relevance by providing access not only to information about the state of the audience but also to further implica- 
tions about the quality of the lecture or of the lecturer. The resulting interpretation (which would be traditionally classified as hyperbolic or metaphorical) would be likely to satisfy the expectations of relevance raised by the utterance. Only if this interpretation fails to satisfy those expectations would the hearer be justified in accessing further contextual assumptions and moving toward a more literal interpretation.

One consequence of this approach to lexical pragmatics is its prediction that, typically, a loose interpretation, based on a few highly accessible encyclopedic properties, will satisfy the hearer's expectation of relevance without a more literal interpretation ever being considered. To illustrate this point further, consider a recent attested example in which the word giant was metaphorically used. When the novelist John Updike died in January 2009, many obituaries contained comments such as the following:

Updike was a giant.

The question is, how should this utterance be understood? The encyclopedic entry for GIANT might provide access to information of the following sort: that giants have extraordinary height, imposing presence, powers beyond those of ordinary humans, stand out from the crowd, and so on. What is interesting about this example is that, even though the word giant is very often used hyperbolically to mean "unusually tall" (as in (7a) above), the utterance of (10) in this particular discourse context would intuitively not be taken to implicate that Updike was very tall. This is so even though giants are stereotypically associated with unusual height, and, moreover, despite the fact that Updike himself happened to be unusually tall. The relevance-theoretic account sheds some light on how this utterance would be understood. In the first place, the expectations of relevance raised by an obituary of a public figure would lead the audience to look for implications having more to do with lifetime achievements than with physical properties. In this case, processing (10) in the context of easily accessible encyclopedic information about Updike's status as a novelist should yield enough implications to satisfy the audience's expectations of relevance without information about his physical stature being considered at all. As a result, an obituarist who did want to draw attention to Updike's height as well as his achievements as a novelist would have to rephrase (10) in such a way as to encourage them to look for further implications. One way of doing this would be as in (11):

(11) Updike was a giant, in every sense of the word.

This reformulation calls for extra processing effort, and according to the relevance-theoretic comprehension heuristic, it should thus encourage a search for extra implications. An alternative strategy used by several of Updike's obituarists was to describe him not simply as a giant, but as a literary giant, or a 
giant of American literature, again calling for more processing effort but creating more precise expectations of relevance that exclude the possibility of considering Updike's physical stature at all.

Returning now to the examples in (1) and (2), I will briefly illustrate how this approach might apply in a case of each type. Consider, first, how the metaphor Robert is a computer might be understood in the following two exchanges:

(12) a. Peter: Is Robert a good accountant?

b. Mary: Robert is a computer.

a. Peter: How good a friend is Robert?

b. Mary: Robert is a computer.

In each case, the encoded sense of computer activates some encyclopedic features of computers that they may share with some humans. Like the best accountants, computers can process large amounts of numerical information and never make mistakes, and so on. Unlike good friends, computers lack emotions, intuitions, common sense, concern for others, and so on. In each case, in interpreting Mary's utterance, Peter constructs an ad hoc concept COMPUTER* which is indicated, though not encoded, by the word computer, such that Robert's falling under this concept has implications that answer the question in (12a) or (13a). Notice that Mary need not have a very precise idea of the implications that Peter will derive, as long as her utterance encourages him to derive the kind of implications that answer his question in the intended way. So the Romantics were right to argue that the figurative meaning of a linguistic metaphor cannot be properly paraphrased. However, this is not because the meaning consists of some non-truth-conditional set of associations or "connotations," as the Romantics believed, but because it involves an "ad hoc" concept that is characterized by its inferential role rather than by a definition, and, moreover, because this inferential role - to a much greater extent than in the case of mere approximations - is left to the hearer to elaborate. In relevancetheoretic terms, metaphorical communication is relatively weak communication (on the notion of weak communication, see Wilson and Sperber 2004, Sperber and Wilson 2008).

Finally, consider how the metaphorical utterance in (2a) above (repeated below for convenience) might be analyzed on this approach:

\section{(2) a. Bill's marriage is on the rocks.}

Let's suppose that this metaphor is being encountered for the first time by someone whose encyclopedic information about marriage contains no conceptual metaphors of the type MARRIAGES ARE JOURNEYS. In this discourse context, the hearer would be entitled to expect (2a) to achieve relevance by carrying 
implications about the state of Bill's marriage, and the most highly activated assumptions in his encyclopedic entry for the concept ON THE ROCKS would be those that apply not only to voyages but also to (some) marriages. For instance, both voyages and marriages have a shorter or longer duration, and may end in more or less desirable or unexpected ways. Both voyages and marriages have participants who may experience various degrees of fear or distress and need various forms of help or comfort if they end in undesirable or unexpected ways. Given this, it should be possible to construct an ad hoc concept ON THE ROCKS*, which is indicated, though not encoded, by the phrase on the rocks, and which is such that the claim that Bill's marriage falls under this concept carries implications about the state of his marriage that make the utterance relevant in the expected way. Similar implications would be carried by a wide range of linguistic metaphors unconnected with the conceptual metaphor MARRIAGES ARE JOURNEYS. For instance, descriptions of Bill's marriage as down the drain, down the plughole, out the window, up in flames, on its last legs, on its deathbed, and so on, would achieve relevance in broadly similar ways (but with subtle differences in the types of implications they activate, which would make the choice between them more than a purely arbitrary affair).

This analysis shows how the linguistic meaning of the phrase on the rocks might be spontaneously adjusted in constructing an interpretation that is relevant in the expected way, even by someone with no previous experience of metaphorical uses linking love affairs to journeys. But of course, many of the examples used in both relevance theory and cognitive linguistics contain metaphorical expressions whose interpretation is more or less a matter of routine. Moreover, cognitive linguists have made valuable contributions to our understanding of how linguistic metaphors often cluster around a central theme, so that a marriage may be described, for instance, not only as on the rocks, but in other terms related to voyages: e.g., in the doldrums, stormy, tempestuous, or becalmed. I will end this section by considering how the repeated use of linguistic metaphors may lead to the setting up of systematic conceptual correspondences of the type that cognitive linguists have so fruitfully studied.

According to relevance theory, the lexical meaning of virtually every word in an utterance is contextually adjusted in order to satisfy expectations of relevance. The adjustment process may be a spontaneous, one-off affair, involving the construction of an "ad hoc" concept that is used once and then forgotten; or it may be regularly and frequently followed, by a few people or a group, until, over time, the resulting "ad hoc" concept may stabilize in a community and give rise to an extra lexicalized sense (Sperber and Wilson 1998, Vega Moreno 2007, Wilson and Carston 2007). As Vega Moreno (2007) shows, routinization affects the amount of processing effort needed to understand an utterance: The more a word is broadened or narrowed in a particular way, the less effort it will cost to follow the same route in the future, and hence 
the more likely it is to be followed by hearers using the relevance-theoretic comprehension heuristic.

Repeated encounters with linguistic metaphors linking two conceptual domains (e.g., the domains of marriage and voyages, or women and flowers) may lead to the setting up of systematic cross-domain correspondences of the type familiar from cognitive linguistics, so that thoughts of marriage may automatically activate aspects of our encyclopedic information about journeys, and thoughts of women may automatically activate aspects of our encyclopedic knowledge of flowers, just as cognitive linguists predict. These cross-domain correspondences would in turn facilitate the production and interpretation of new linguistic metaphors based on the same conceptual activation patterns, resulting in thematically related clusters of linguistic metaphors, just as cognitive linguists predict. On relevance theory's account, these patterns of activation would ultimately derive from the repeated use of linguistic metaphors, and thus arise for communicative rather than purely cognitive reasons.

\section{Broader implications}

As Gibbs and Tendahl (2008: 1824) point out, relevance theory and cognitive linguistics differ in some of their goals and working assumptions. These differences have often obscured the broader parallels in their approaches to metaphor, and to lexical meaning in general. Having drawn attention to some of these parallels and argued that in many respects the two approaches are complementary rather than contradictory, I will end by outlining some of the differences between them and considering how they might be resolved.

As noted above, a central difference is that cognitive linguists see linguistic metaphors as depending on pre-existing cross-domain mappings, whereas relevance theory suggests that cross-domain conceptual mappings may result from repeated use of linguistic metaphors, but are not essential to either the production or the interpretation of metaphors. More generally, relevance theorists see metaphors as arising primarily in linguistic communication, whereas cognitive linguists see them as arising primarily in thought. I have suggested that the two approaches could be reconciled by finding evidence that some cross-domain mappings arise in language and others in thought.

However, these differences in the treatment of metaphor can be traced to a more fundamental difference in the relative priority that the two approaches assign to the study of communication (as opposed to cognition). Both relevance theory and cognitive linguistics reject the Conduit metaphor (i.e., the code model of communication) as inadequate, and both advocate an inferential approach to communication. But while cognitive linguists tend to assume that understanding utterances is simply a matter of applying general-purpose cog- 
nitive and linguistic abilities to the communicative domain, relevance theorists have argued that understanding utterances involves special-purpose inferential procedures that apply only in the communicative domain. According to relevance theory, utterance comprehension involves not merely drawing commonsense inferences, but drawing inferences about the communicator's meaning, which is a complex mental state consisting of both an informative and a communicative intention. Inferring this meaning therefore crucially involves an ability to "mindread" (i.e., to infer the mental states of others on the basis of their behavior), and there is a growing body of evidence that "mindreading" is a special-purpose inferential ability with its own specific patterns of development and breakdown. ${ }^{4}$ In fact, relevance theorists have gone even further, and argued that the ability to infer communicators' meanings involves more specialized inferential procedures attuned to regularities that exist only in the communicative domain (Sperber and Wilson 2002). ${ }^{5}$ These regularities include the fact described in the Communicative Principle of Relevance, that utterances (and other acts of overt communication) raise expectations of relevance not raised by ordinary actions, and underpin the relevance-theoretic comprehension heuristic, a special-purpose inferential procedure that yields valid results only when applied to overt communicative acts. These differences in the treatment of overt communication in relevance theory and cognitive linguistics could be resolved by further developmental or neuropsychological evidence.

It is worth pointing out that while waiting for this issue to be resolved, cognitive linguistics still stands to benefit from relevance theory in two important ways. In the first place, cognitive linguists face a major challenge in explaining how hearers not only understand most metaphorical utterances, but typically understand them in the way the speaker intended. A pragmatic approach such as relevance theory, which fits well with many of the assumptions of cognitive linguistics, suggests a natural way of explaining how the inferences hearers draw in communicative situations might be suitably constrained. In the second place, although cognitive linguists and relevance theorists have both emphasized the importance of inference in metaphor interpretation, cognitive linguists face a major challenge in explaining how the inferences that hearers draw in the course of utterance comprehension are properly warranted. Lakoff and Johnson (2003: 246) see the key to their approach to conceptual metaphor as lying in the fact that "we systematically use inference patterns from one conceptual domain to reason about another." But as both conceptual metaphor theorists and blending theorists recognize, not all the inferential patterns from one conceptual domain are valid when carried over to the other. What is needed is some way of distinguishing mere conceptual associations or co-activations from valid inferences. Here again, relevance theory suggests a possible way out. What makes it valid to draw a particular inference in interpreting a given 
utterance is that, unless this inference were valid, the utterance would not yield enough implications to be relevant in the expected way. Thus, a speaker who formulates her utterance in such a way as to encourage her hearer to derive a certain inference is largely responsible for its validity. Thus, here again, a pragmatic account of metaphor of the type proposed by relevance theory might have worthwhile implications for cognitive linguistics.

\section{Notes}

* A version of this paper was presented at the 11th Conference of the Pragmatics Society of Japan. I would like to thank Masa-aki Yamanashi, Isao Higashimori, and the members of the society for wonderful hospitality during my visit there. I am also very grateful to Yuji Nishiyama, Tomoko Matsui, Michiko Takeuchi, Seiji Uchida, Larry Schourup, Robyn Carston, Dan Sperber, Ray Gibbs, Beate Hampe, Seana Coulson, Hans-Joerg Schmid and Cornelia Müller for valuable discussion and comments. The research was supported by CSMN (University of Oslo) and the Norway Research Council.

1. For cognitive linguistics approaches to metaphor, see Lakoff and Johnson (1987, 2003), Grady (1997), Gibbs (1998), Fauconnier and Turner (2002, 2008), Ruiz de Mendoza and Perez Hernandez (2003), Hampe (2005) and Müller (2008); see also McGlone (2001).

2. For recent relevance-theoretic treatments of metaphor, see e.g., Carston (2002), Higashimori (2002), Wilson and Sperber (2002), Vega Moreno (2007), Wilson and Carston (2007, 2008), and Sperber and Wilson (2008).

3. For fuller exposition of relevance theory, and comparison with alternative approaches, see Sperber and Wilson (1995), Carston (2002), and Wilson and Sperber (2004).

4. See Astington et al. (1988); Wellman, Cross, and Watson (2001); Sodian (2004); Matsui et al. (2006, 2009).

5. Further evidence that communication is a special-purpose ability is provided in Southgate, van Maanen and Csibra (2007); Liszkowski, Carpenter, and Tomasello (2008); Southgate, Chevallier, and Csibra (2009); and Wilson (2009, forthcoming).

\section{References}

Astington, J., P. Harris, \& D. Olson. (eds), 1988. Developing Theories of Mind. New York: Cambridge University Press.

Barsalou, L. 1987. The instability of graded structure in concepts. In U. Neisser (ed.), Concepts and Conceptual Development, 101-140. New York: Cambridge University Press.

Barsalou, L. 1993. Flexibility, structure and linguistic vagary in concepts. In A. Collins, S. Gathercole, \& A. Conway (eds), Theories of Memory, 29-101. Hove: Lawrence Erlbaum.

Carston, R. 2002. Thoughts and Utterances: The Pragmatics of Explicit Communication. Oxford: Blackwell.

Fauconnier, G. \& M. Turner. 2002. The Way we Think: Conceptual Blending and the Mind's Hidden Complexities. New York: Basic Books.

Fauconnier, G. \& M. Turner. 2008. Rethinking metaphor. In R. Gibbs (ed.), The Cambridge Handbook of Metaphor and Thought, 53-66. New York: Cambridge University Press. 
Gibbs, R. 1998. The fight over metaphor in thought and language. In N. Katz, C. Cacciari, R. Gibbs, \& M. Turner (eds), Figurative Language and Thought, 88-118. New York: Oxford University Press.

Gibbs, R. \& M. Tendahl. 2006. Cognitive effort and effects in metaphor comprehension: Relevance theory and psycholinguistics. Mind \& Language 21(3). 379-403.

Glucksberg, S. 2001. Understanding Figurative Language: From Metaphors to Idioms. New York: Oxford University Press.

Grady, J. E. 1997. TheOrIES ARE BUILDINGs revisited. Cognitive Linguistics 8. 267-290.

Hampe, B. 2005. On the role of iconic motivation in conceptual metaphor: Has metaphor theory come full circle? In C. Maeder, O. Fischer, \& W. Herlofsky (eds), Outside in, Inside-out: Iconicity in Language and Literature 4, 39-66. Amsterdam: John Benjamins.

Higashimori, I. 2002. Metaphor understanding in relevance theory: From loan concept metaphor to TIME is SPACE metaphor. Paper presented at the 3rd International Maastricht Lódź Duo Colloquium on "Translation and Meaning," Łódź, Poland, 22-24 September.

Lakoff, G. \& M. Johnson. 1980. Metaphors We Live By. Chicago: University of Chicago Press. (Second edition, with a new "Afterword," 2003.)

Lasersohn, P. 1999. Pragmatic halos. Language 75. 522-551.

Liszkowski, U., M. Carpenter, \& M. Tomasello. 2008. Twelve-month-olds communicate helpfully and appropriately for knowledgeable and ignorant partners. Cognition 108. 732-739.

McGlone, M. 2001. Concepts as metaphors. In S. Glucksberg, Understanding Figurative Language: From Metaphors to Idioms, 90-115. New York: Oxford University Press.

Matsui, T., T. Yamamoto, \& P. McCagg. 2006. On the role of language in children's early understanding of others as epistemic beings. Cognitive Development 21. 158-173.

Matsui, T., H. Rakoczy, Y. Miura, \& M. Tomasello. 2009. Understanding of speaker certainty and false-belief reasoning: A comparison of Japanese and German preschoolers. Developmental Science 12. 602-13.

Müller, C. 2008. Metaphors Dead and Alive, Sleeping and Waking: A Dynamic View. Chicago: University of Chicago Press.

Ruiz de Mendoza Ibáñez, F. \& L. Perez Hernandez. 2003. Cognitive operations and pragmatic implication. In K. U. Panther \& L. Thornburg (eds.), Metonymy and Pragmatic Inferencing, 23-49. Amsterdam: John Benjamins.

Sodian, B. 2004. Theory of mind: The case for conceptual development. In W. Schneider, R. Schumann-Hengsteler, \& B. Sodian (eds.), Young Children's Cognitive Development, 95-130. London: Routledge.

Southgate, V., C. Chevallier, \& G. Csibra. 2009. Sensitivity to communicative relevance tells young children what to imitate. Developmental Science. 1013-1019.

Southgate, V., C. van Maanen, \& G. Csibra. 2007. Infant Pointing: Communication to Cooperate or Communication to Learn? Child Development 78. 735-740.

Sperber, D. \& D. Wilson. 1995. Relevance: Communication and Cognition (2nd edition). Oxford: Blackwell.

Sperber, D. \& D. Wilson. 1998. The mapping between the mental and the public lexicon. In P. Carruthers \& J. Boucher (eds.), Language and Thought, 184-200. New York: Cambridge University Press.

Sperber, D. \& D. Wilson. 2002. Pragmatics, modularity and mindreading. Mind \& Language 17(1/2). 3-23.

Sperber, D. \& D. Wilson. 2008. A deflationary account of metaphors. In R. Gibbs (ed.), The Cambridge Handbook of Metaphor and Thought, 84-105. New York: Cambridge University Press.

Tendahl, M. \& R. Gibbs. 2008. Complementary perspectives on metaphor: Cognitive linguistics and relevance theory. Journal of Pragmatics 40. 1823-1864. 
Vega Moreno, R. 2007. Creativity and Convention: The Pragmatics of Everyday Figurative Speech. Amsterdam: John Benjamins.

Wellman, H., D. Cross, \& J. Watson. 2001. Meta-analysis of theory of mind development: The truth about false belief. Child Development 72. 655-684.

Wilson, D. 2009. Irony and metarepresentation. UCL Working Papers in Linguistics 21. 183-226.

Wilson, D. Forthcoming. Pragmatic processes and metarepresentational abilities: The case of verbal irony. To appear in T. Matsui (ed.), Pragmatics and Theory of Mind. Amsterdam: John Benjamins.

Wilson, D. \& R. Carston. 2007. A unitary approach to lexical pragmatics: Relevance, inference and ad hoc concepts. In N. Burton-Roberts (ed.), Pragmatics, 230-259. Basingstoke: Palgrave.

Wilson, D. \& R. Carston. 2008. Metaphor and the 'Emergent Property' Problem: A RelevanceTheoretic Approach. The Baltic International Yearbook of Cognition, Logic and Communication [Online], 3 (2007). <http://www.thebalticyearbook.org/>.

Wilson, D. \& D. Sperber. 2002. Truthfulness and relevance. Mind 111(443). 583-632.

Wilson, D. \& D. Sperber. 2004. Relevance Theory. In L. Horn \& G. Ward (eds.), The Handbook of Pragmatics, 607-632. Oxford: Blackwell.

Corresponding address: deirdre.wilson@ucl.ac.uk 